\title{
LETTER
}

\section{Chronic lymphocytic leukemia}

\section{COVID-19 among fit patients with CLL treated with venetoclax- based combinations}

\author{
Moritz Fürstenau $\mathbb{( D}^{1}$ - Petra Langerbeins ${ }^{1}$ - Nisha De Silva ${ }^{1}$ Anna Maria Fink ${ }^{1}$ - Sandra Robrecht ${ }^{1}$. \\ Julia von Tresckow ${ }^{1}$. Florian Simon ${ }^{1}$ Karin Hohloch ${ }^{2,3}$ - Jolanda Droogendijk ${ }^{4}$ - Marjolein van der Klift ${ }^{5}$. \\ Ellen van der Spek ${ }^{6}$. Thomas Illmer ${ }^{7}$ - Björn Schöttker ${ }^{8}$ - Kirsten Fischer ${ }^{1}$ - Clemens M. Wendtner (iD ${ }^{9}$. \\ Eugen Tausch $^{10} \cdot$ Stephan Stilgenbauer $^{10,11} \cdot$ Carsten U. Niemann $\mathbb{D}^{12} \cdot$ Michael Gregor $^{13} \cdot$ Arnon P. Kater $^{14}$. \\ Michael Hallek ${ }^{1,15}$ - Barbara Eichhorst ${ }^{1}$
}

Received: 3 June 2020 / Revised: 11 June 2020 / Accepted: 16 June 2020 / Published online: 29 June 2020

(c) The Author(s) 2020. This article is published with open access

\section{To the Editor:}

With more than 5 million proven infections and more than 300,000 associated deaths worldwide [1], the SARS-CoV-2 pandemic poses unprecedented challenges to health-care professionals and especially those treating and caring for patients with malignant hematological diseases. These patients often have multiple different risk factors for severe infections [2]. Chronic lymphocytic leukemia (CLL) is the most common form of leukemia and infections are a known contributor to morbidity and mortality due to a disease-

These authors contributed equally: Moritz Fürstenau, Petra Langerbeins

Moritz Fürstenau

moritz.fuerstenau@uk-koeln.de

1 Department I of Internal Medicine, Center for Integrated Oncology Aachen Bonn Cologne Duesseldorf, German CLL Study Group, University Hospital Cologne, University of Cologne, Cologne, Germany

2 Department of Internal Medicine, Hematology and Medical Oncology, Kantonsspital Graubünden, Chur, Switzerland

3 Department of Hematology and Oncology, University Hospital Göttingen, Göttingen, Germany

4 Division of Hematology and Oncology, Elisabeth-TweeSteden Ziekenhuis, Tilburg, The Netherlands

5 Division of Hematology and Oncology, Amphia Ziekenhuis Breda, Breda, The Netherlands

6 Department of Internal Medicine, Ziekenhuis Rijnstate, Arnhem, The Netherlands

7 BAG Freiberg-Richter, Jacobasch, Wolf, Illmer, Dresden, Germany inherent immunodeficiency [3, 4]. Considering this multifactorial immune defect, it appears conceivable that patients with CLL are more susceptible to infections with SARS-CoV2 and more likely to develop severe courses of the associated respiratory disease COVID-19, especially when under additional immunosuppression by chemoimmunotherapy (CIT). Few case reports on COVID-19 in CLL patients from countries with suspected different prevalence rates of COVID-19 have been published so far. The publications report a patient after first-line treatment with single-agent chlorambucil, a case series with four treatment-naive CLL patients, a case series of eight patients on Bruton tyrosine kinase (BTK) inhibitors and most recently a heterogeneously treated population of four patients from the Hospital Clinic of Barcelona [5-8]. While it has been hypothesized that the BTK inhibitor ibrutinib might have protective effects against COVID-19 by attenuating

8 Hämatologisch-onkologische Schwerpunktpraxis Würzburg, Würzburg, Germany

9 Department of Hematology, Oncology, Immunology, Palliative Care, Infectious Diseases and Tropical Medicine, German CLL Study Group, Munich Clinic Schwabing, Munich, Germany

10 Department of Internal Medicine III, University of Ulm, Ulm, Germany

11 Department of Internal Medicine I, Saarland University Medical School, Homburg/Saar, Germany

12 Department of Hematology, Rigshospitalet, Copenhagen University Hospital, Copenhagen, Denmark

13 Division of Hematology, Cantonal Hospital of Lucerne, Lucerne, Switzerland

14 Department of Hematology, Cancer Center Amsterdam, Amsterdam University Medical Centers, University of Amsterdam, Amsterdam, The Netherlands

15 Cologne Excellence Cluster on Cellular Stress Response in AgingAssociated Diseases (CECAD), University of Cologne, Cologne, Germany 
hyperinflammatory responses, there is currently no data on COVID-19 in patients receiving venetoclax-based treatments [7, 9]. A recent study has suggested a reduction of CLLinherent immunosuppression after successful treatment with venetoclax-based regimens [10]. In light of these data we sought to determine the incidence, severity, and possible risk factors of COVID-19 cases in a well-defined cohort of patients with CLL receiving venetoclax-based combination treatments as first-line therapy in a prospective clinical trial.

The GAIA/CLL13 trial (NCT02950051) is a multicenter phase 3 investigator-initiated trial with sites in nine European countries plus Israel. From December 2016 to September 2019,926 physically fit and treatment-naive patients were randomized into four treatment arms. In the standard arm, CIT with fludarabine, cyclophosphamide plus rituximab (FCR, patients $\leq 65$ years) or bendamustine plus rituximab (BR, patients $>65$ years) is administered. In the experimental arms 12 cycles of venetoclax-containing regimes are tested: venetoclax plus rituximab (RVe), venetoclax plus obinutuzumab $(\mathrm{GVe})$ and venetoclax plus ibrutinib and obinutuzumab (GIVe). Patients with del(17p) or TP53 mutation were not eligible.

Between March and April 2020 seven patients within the GAIA/CLL13 trial developed COVID-19, one in the CIT arm and six patients in the experimental treatment arms (Table 1). The baseline characteristics show a median age of 61 years (range 52-78) and in accordance with the inclusion criteria of the study only few comorbidities and no TP53 aberrations were documented. All but one patient had completed study treatment at the time point of COVID-19 diagnosis with a median time after end of treatment of 22 (range 1-30) months. All seven patients were tested positive for SARSCoV-2 by PCR collected from nasopharyngeal swabs. While one patient was isolated in home quarantine, six of seven patients $(85.7 \%)$ had to be hospitalized and two (28.6\%) required treatment on an intensive care unit (ICU), only one patient required invasive mechanical ventilation (Table 1). Two patients died as a result of their SARS-CoV-2 infection, one 58-year-old patient (patient 4) after a prolonged treatment with mechanical ventilation (52 days) on an ICU and a 78year-old patient (patient 7) who decided against ICU treatment and was treated with best supportive care.

We assessed different surrogate markers for immune function to elucidate the mechanisms of susceptibility to COVID-19 in our patient cohort (Fig. 1). The frequency of infections observed after start of study treatment differed strongly between the patients. Three patients had a history of multiple $(\geq 2)$ infections per year since start of study treatment and six of seven $(85.7 \%)$ patients had at least one episode of neutropenia (Fig. 1a). An analysis of immunoglobulin levels before and after study treatment revealed a substantial humoral immune deficiency with abnormal pretreatment $\mathrm{IgG}$ levels in six of seven patients (85.7\%)
(Fig. 1b). In line with previous data, we show a decrease of the initially expanded $\mathrm{CD} 3+, \mathrm{CD} 4+$ and $\mathrm{CD} 8+\mathrm{T}$-cell populations in the course of study treatment (Fig. 1c).

Between March and April 2020, we observed seven cases of COVID-19 among 926 patients in our phase 3 GAIA/CLL13 trial. The estimated cumulative incidence of 755.9 COVID-19 cases per 100,000 persons appears high when compared to age-specific (60-79 years) incidence rates, for instance in Germany (female: 169.5; male: 209) [11]. We also observed a substantially higher hospitalization rate of $85.7 \%$ in our patients compared to a study that estimated patients requiring hospitalization at $11.8 \%$ (60-69 years) and $16.6 \%$ (70-79 years), respectively [12].

This difference is likely due to the multifactorial immune suppression in our patients (Fig. 1). Besides an increased frequency of infections in some and CLLassociated hypogammaglobulinaemia in most patients we also found reduced CD4+ and CD8 + T-cell subpopulations. Adding to this quantitative cellular immune deficiency, $\mathrm{T}$ cells are known to be functionally impaired in CLL [13]. In COVID-19, decreased levels of CD4+ and $\mathrm{CD} 8+\mathrm{T}$ cells were associated with more severe disease courses, suggesting that pre-existing cellular defects might lead to an impaired T-cell response in infected individuals with CLL [14]. Furthermore, in this relatively small case series, the most severe respiratory failures were observed in patients who were still under treatment (patient 7) or had stopped treatment 2 months before (patient 4), which might reflect more severe immune deficiency during ongoing combination treatment. However, the comparably high incidence and hospitalization rate could also reflect a more stringent observation and precautious hospitalization of these patients treated within a clinical trial, though none of the patients had an asymptomatic SARS-CoV-2 infection and the number of unknown cases could be even higher.

Despite the high hospitalization rate, the here observed case fatality rate of $28.6 \%$ is similar to the recently published cohort of BTK inhibitor-treated patients with CLL $(25 \%)$ and lower than in the case series of four treatmentnaive patients, of which three had a fatal outcome $(75 \%)$ $[6,7]$. The different cases fatality rates observed between the treatment-naive cohort and our study are most likely due to the different ages of the analyzed populations. All patients with fatal COVID-19 courses described in the publication by Paneesha et al. were between 79 and 81 years of age compared to a median age of 61 years in our cohort. Furthermore, our study population comprises of comparably fit CLL patients with few comorbidities (median CIRS score: 2 [range 0-5]). However, five of our patients had additional risk factors (hypertension, chronic respiratory diseases, cardiovascular disease) for severe COVID-19 as established by recent meta-analyses [15]. 
Table 1 Patient and treatment characteristics.

\begin{tabular}{|c|c|c|c|c|c|c|c|}
\hline & Patient 1 & Patient 2 & Patient 3 & Patient 4 & Patient 5 & Patient 6 & Patient 7 \\
\hline \multicolumn{8}{|l|}{ Baseline characteristics } \\
\hline Age, years & 52 & 60 & 68 & 58 & 63 & 61 & 78 \\
\hline Sex & M & $\mathrm{F}$ & M & M & M & $\mathrm{F}$ & $\mathrm{F}$ \\
\hline Country & GER & NL & NL & $\mathrm{CH}$ & GER & GER & NL \\
\hline \multicolumn{8}{|l|}{ CLL characteristics } \\
\hline Treatment & $\mathrm{RVe}$ & $\mathrm{RVe}$ & GIVe & GIVe & GVe & FCR & $\mathrm{GVe}$ \\
\hline Date of CLL diagnosis & $07 / 2013$ & $02 / 2013$ & $03 / 2018$ & $08 / 2018$ & $03 / 2017$ & $07 / 2011$ & $09 / 2011$ \\
\hline $\begin{array}{l}\text { Time from CLL diagnosis } \\
\text { to treatment, months }\end{array}$ & 43 & 56 & 7 & 6 & 1 & 70 & 96 \\
\hline Binet stage at screening & $\mathrm{B}$ & $\mathrm{A}$ & B & $\mathrm{B}$ & $\mathrm{C}$ & $\mathrm{B}$ & A \\
\hline \multicolumn{8}{|l|}{ FISH at screening } \\
\hline $\operatorname{Del}(11 q)$ & $\mathrm{N}$ & $\mathrm{Y}$ & $\mathrm{Y}$ & $\mathrm{N}$ & $\mathrm{N}$ & $\mathrm{N}$ & $\mathrm{N}$ \\
\hline Trisomy 12 & $\mathrm{~N}$ & $\mathrm{~N}$ & $\mathrm{~N}$ & $\mathrm{~N}$ & $\mathrm{~N}$ & $\mathrm{~N}$ & $\mathrm{~N}$ \\
\hline $\operatorname{Del}(13 q)$ & $\mathrm{Y}$ & $\mathrm{N}$ & $\mathrm{N}$ & $\mathrm{N}$ & $\mathrm{Y}$ & $\mathrm{Y}$ & $\mathrm{Y}$ \\
\hline $\begin{array}{l}\text { IGHV mutational status at } \\
\text { screening }\end{array}$ & Unmut. & Unmut. & Unmut. & Mut. & Unmut. & Mut. & Mut. \\
\hline \multicolumn{8}{|l|}{ Comorbidities at screening } \\
\hline $\begin{array}{l}\text { Cumulative Ilness Rating } \\
\text { Scale (CIRS) score }\end{array}$ & 5 & 4 & 2 & 0 & 2 & 3 & 2 \\
\hline Hypertension & $\mathrm{N}$ & $\mathrm{Y}$ & $\mathrm{Y}$ & $\mathrm{N}$ & $\mathrm{N}$ & $\mathrm{Y}$ & $\mathrm{N}$ \\
\hline Diabetes & $\mathrm{N}$ & $\mathrm{N}$ & $\mathrm{N}$ & $\mathrm{N}$ & $\mathrm{N}$ & $\mathrm{N}$ & $\mathrm{N}$ \\
\hline Asthma & Y & $\mathrm{N}$ & $\mathrm{N}$ & $\mathrm{N}$ & $\mathrm{N}$ & $\mathrm{N}$ & $\mathrm{N}$ \\
\hline COPD & $\mathrm{N}$ & $\mathrm{N}$ & $\mathrm{N}$ & $\mathrm{N}$ & $\mathrm{N}$ & $\mathrm{N}$ & $\mathrm{N}$ \\
\hline Cardiovascular Diseases & $\mathrm{N}$ & $\mathrm{N}$ & $\mathrm{N}$ & $\mathrm{N}$ & $\mathrm{Y}$ & $\mathrm{N}$ & $\mathrm{N}$ \\
\hline Obesity (BMI $\geq 30 \mathrm{~kg} / \mathrm{m}^{2}$ ) & $\mathrm{N}$ & $\mathrm{N}$ & $\mathrm{N}$ & $\mathrm{N}$ & $\mathrm{N}$ & $\mathrm{N}$ & $\mathrm{N}$ \\
\hline \multicolumn{8}{|l|}{ COVID-19 presentation } \\
\hline \multicolumn{8}{|l|}{ Symptoms at first presentation } \\
\hline Fever & Y & $\mathrm{Y}$ & $\mathrm{N}$ & $\mathrm{N}$ & $\mathrm{N}$ & $\mathrm{N}$ & Y \\
\hline Cough & Y & $\mathrm{N}$ & $\mathrm{Y}$ & Y & $\mathrm{N}$ & Y & $\mathrm{Y}$ \\
\hline Fatigue & $\mathrm{N}$ & $\mathrm{Y}$ & $\mathrm{N}$ & $\mathrm{Y}$ & $\mathrm{N}$ & $\mathrm{Y}$ & $\mathrm{N}$ \\
\hline Dyspnea & $\mathrm{N}$ & $\mathrm{Y}$ & $\mathrm{N}$ & $\mathrm{Y}$ & $\mathrm{N}$ & $\mathrm{N}$ & $\mathrm{N}$ \\
\hline Sore throat & $\mathrm{N}$ & $\mathrm{N}$ & $\mathrm{Y}$ & $\mathrm{N}$ & $\mathrm{N}$ & $\mathrm{N}$ & $\mathrm{N}$ \\
\hline Rhinitis & $\mathrm{N}$ & $\mathrm{N}$ & $\mathrm{N}$ & $\mathrm{N}$ & $\mathrm{Y}$ & $\mathrm{N}$ & $\mathrm{N}$ \\
\hline Anosmia/Ageusia & $\mathrm{N}$ & $\mathrm{N}$ & $\mathrm{N}$ & $\mathrm{N}$ & $\mathrm{N}$ & $\mathrm{N}$ & $\mathrm{N}$ \\
\hline $\begin{array}{l}\text { Bilateral pulmonary } \\
\text { infiltrates on CT/X-ray }\end{array}$ & Y & Y & $\mathrm{Y}$ & $\mathrm{Y}$ & ND & $\mathrm{Y}$ & $\mathrm{Y}$ \\
\hline $\begin{array}{l}\text { Time EOT to COVID- } \\
19, \text { months }\end{array}$ & 26 & 18 & 3 & 1 & 27 & 30 & NA \\
\hline \multicolumn{8}{|c|}{ COVID-19 treatment and outcome } \\
\hline Hospitalization & $\mathrm{Y}$ & $\mathrm{Y}$ & Y & $\mathrm{Y}$ & $\mathrm{N}$ & $\mathrm{Y}$ & $\mathrm{Y}$ \\
\hline Duration of stay, days & 16 & 12 & 6 & 55 & NA & 12 & 14 \\
\hline Oxygen support & Y & Y & Y & Y & $\mathrm{N}$ & $\mathrm{N}$ & $\mathrm{Y}$ \\
\hline Type of ventilation/support & HFNC & $\mathrm{NC}$ & $\mathrm{NC}$ & $\mathrm{TI}$ & None & None & $\mathrm{NC}$ \\
\hline Outcome & Resolved & Resolved & Resolved & Death & Resolved & Resolved & Death \\
\hline
\end{tabular}

$Y$ yes, $N$ no, $N A$ not applicable, $N D$ not done. $M$ male, $F$ female. $G E R$ Germany, $N L$ The Netherlands, $C H$ Switzerland. $R V e$ rituximab, venetoclax, GIVe obinutuzumab, ibrutinib, venetoclax, GVe obinutuzumab, venetoclax, FCR fludarabine, cyclophosphamide, rituximab. Unmut. unmutated, Mut. mutated. HFNC high flow nasal cannula, NC nasal cannula, TI tracheal intubation. 
Fig. 1 Individual treatment courses and parameters of immune function. a The vertical axis represents absolute neutrophil counts (ANC), blue boxes show treatment regimen and duration (RVe rituximab, venetoclax, GVe obinutuzumab, venetoclax, GIVe

obinutuzumab, ibrutinib, venetoclax, FCR fludarabine, cyclophosphamide, rituximab). Infections after study inclusion and onset of COVID-19 are depicted in orange boxes. The threshold for neutropenia is shown in yellow. b The vertical axis shows levels of immunoglobulins before (baseline) and after treatment (final restaging), normal ranges are indicated in green. Each cross/line represents one patient. c Changes in T-cell subpopulations in the course of first-line treatment. Patients on venetoclax combinations are depicted in black, the patient on FCR is shown in orange. Blue bars represent median values of all analyzed patients at each time point.
A

Patient 1

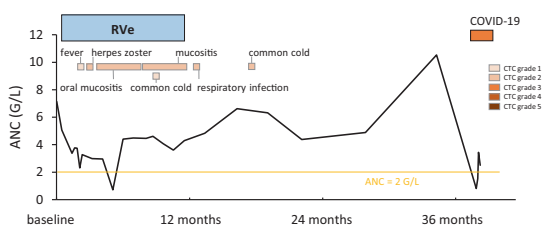

Patient 2

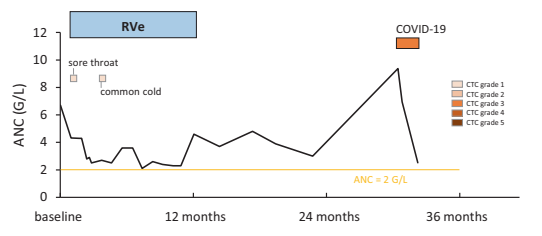

Patient 3

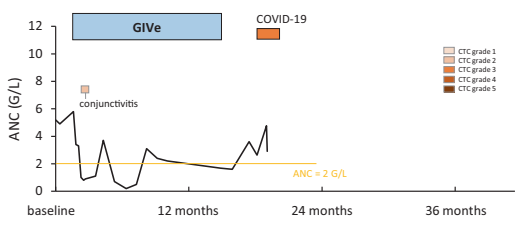

Patient 4

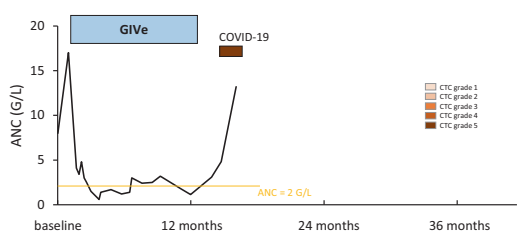

Patient 5

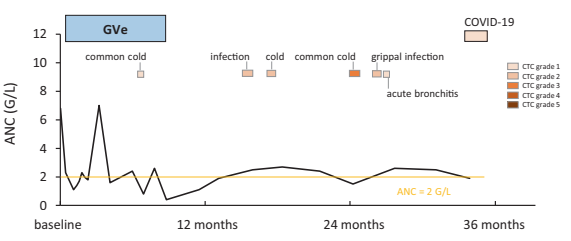

Patient 6

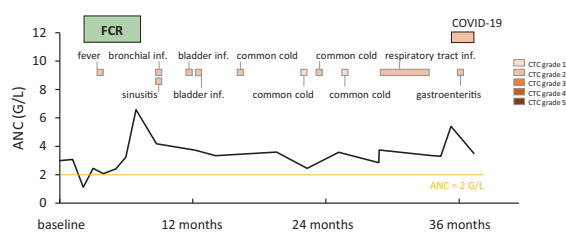

Patient 7

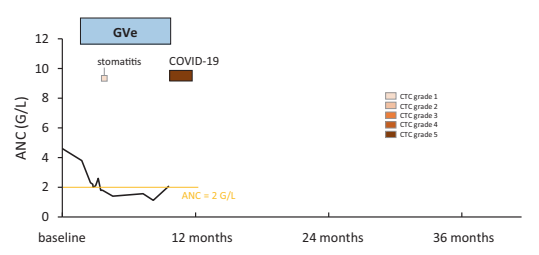

B
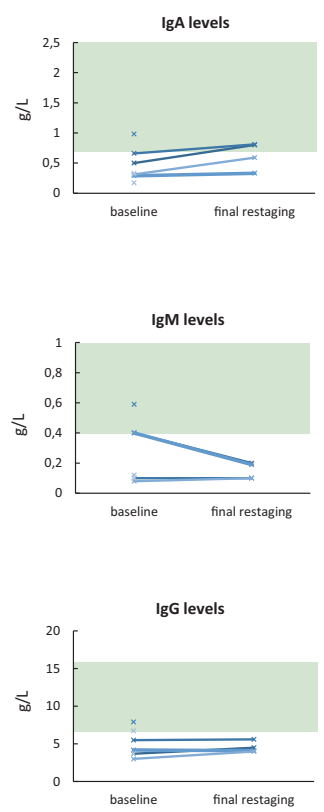

C

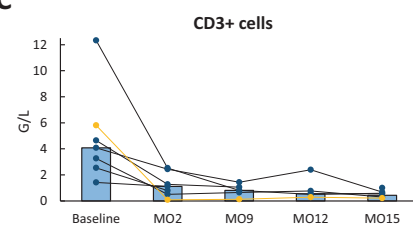

$\mathrm{CD} 4+\mathrm{T}$ cells

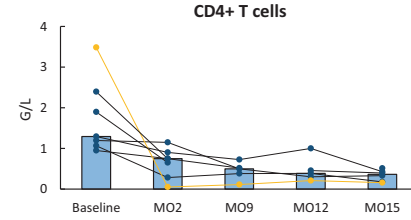

CD8+ T cells
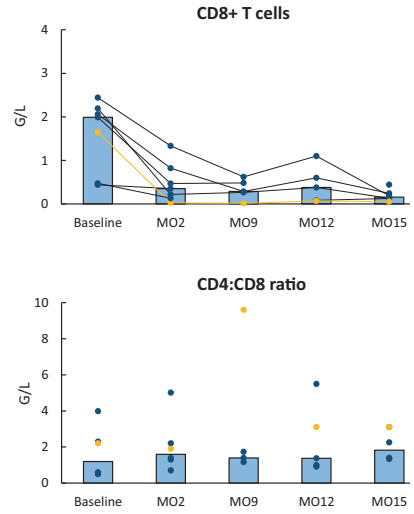
To our knowledge, we here report the first analysis of COVID-19 in CLL patients receiving venetoclax-based combinations and CIT as first-line treatment within a large randomized controlled trial. This analysis suggests an increased rate of COVID-19 as well as an increased hospitalization rate in fit patients with CLL. Despite their various CLL-associated immune defects, the majority of patients recovered from COVID-19. As this is an ongoing clinical trial, a benefit-risk assessment is continuously performed by an independent data and safety monitoring board (DSMB). At this time the DSMB had no objection against continuation of the trial or subjects to continue treatment as allocated.

Acknowledgements This study is supported by research funding from Hoffmann-La Roche, AbbVie and Janssen-Cilag Ltd to the German CLL Study Group. The GAIA/CLL13 trial is sponsored by the German CLL Study Group in close cooperation with HOVON, the Nordic CLL Study Group (NCLLSG), the Swiss Group for Clinical Cancer Research (SAKK), Cancer Trials Ireland and the Israeli CLL Study Group. The Data and Safety Monitoring Board (DSMB) that supervised the trial is an independent body of scientists including Carol Moreno (Barcelona, Spain), Monica Else (London, UK), Daniel Catovsky (London, UK) and Paolo Ghia (Milano, Italy). Open access funding provided by Projekt DEAL.

\section{Compliance with ethical standards}

Conflict of interest MF, NDS, AMF, SR, KH, JD, MvdK, TI, BS, and MG have nothing to disclose. PL reports grants, personal fees, travel support from and consultancy for Janssen-Cilag, travel support from Roche, consultancy for Abbvie and Sunesis outside the submitted work. JvT reports grants and personal fees from Hoffmann-La Roche, AbbVie, Janssen-Cilag during the conduct of the study and outside the submitted work. FS reports travel support from Gilead. EvdS. reports personal fees from Amgen outside the submitted work. KF reports travel grants from Roche and honoraria from Roche and Abbvie. CMW reports grants and personal fees from Hoffmann-La Roche, AbbVie, Janssen-Cilag during the conduct of the study and outside the submitted work. ET reports grants and personal fees (advisory board, speakers bureau) from Roche and Abbvie and personal fees and nonfinancial support (advisory board, speakers bureau, travel support) from Janssen. SS reports grants, personal fees, and non-financial support from AbbVie, AstraZeneca, Celgene, Gilead, GSK, Hoffmann-La Roche, Janssen, Novartis, Pharmacyclics, Sunesis and personal fees and non-financial support from Verastem during the conduct of the study and outside the submitted work. CUN reports grants and personal fees from Abbvie, Janssen, AstraZeneca, grants from Novo Nordisk Foundation and the Danish Cancer Society, all outside the submitted work. APK reports research grants from, appeared on an ad board for and received speaker's fees from Abbvie, Janssen and Genentech. MH reports grants, non-financial support and personal fees (honoraria; speaker's bureau and/or advisory board) from Roche, Gilead, Mundipharma, Janssen, Celgene, Pharmacyclics, AbbVie outside the submitted work and grants from Roche, Janssen and Abbvie during the conduct of the study. BE reports personal fees and research funding from Janssen-Cilag, Abbvie and Roche, research funding from Beigene and personal fees from Novartis, Celgene, ArQule, AstraZeneca, Oxford Biomedica (UK) and Adaptive Biotechnologies, all outside the submitted work.

Publisher's note Springer Nature remains neutral with regard to jurisdictional claims in published maps and institutional affiliations.
Open Access This article is licensed under a Creative Commons Attribution 4.0 International License, which permits use, sharing, adaptation, distribution and reproduction in any medium or format, as long as you give appropriate credit to the original author(s) and the source, provide a link to the Creative Commons license, and indicate if changes were made. The images or other third party material in this article are included in the article's Creative Commons license, unless indicated otherwise in a credit line to the material. If material is not included in the article's Creative Commons license and your intended use is not permitted by statutory regulation or exceeds the permitted use, you will need to obtain permission directly from the copyright holder. To view a copy of this license, visit http://creativecommons. org/licenses/by/4.0/.

\section{References}

1. Dong E, Du H, Gardner L. An interactive web-based dashboard to track COVID-19 in real time. Lancet Infect Dis. 2020;20: $533-4$.

2. He W, Chen L, Chen L, Yuan G, Fang Y, Chen W, et al. COVID19 in persons with haematological cancers. Leukemia. 2020;34:1637-45.

3. Andersen MA, Eriksen CT, Brieghel C, Biccler JL, Cunha-Bang $\mathrm{CD}$, Helleberg $\mathrm{M}$, et al. Incidence and predictors of infection among patients prior to treatment of chronic lymphocytic leukemia: a Danish nationwide cohort study. Haematologica. 2018;103: e300-3.

4. Forconi F, Moss P. Perturbation of the normal immune system in patients with CLL. Blood. 2015;126:573-81.

5. Jin XH, Zheng KI, Pan KH, Xie YP, Zheng MH. COVID-19 in a patient with chronic lymphocytic leukaemia. Lancet Haematol. 2020;7:e351-2.

6. Paneesha S, Pratt G, Parry H, Moss P. Covid-19 infection in therapy-naive patients with B-cell chronic lymphocytic leukemia. Leuk Res. 2020;93:106366.

7. Thibaud S, Tremblay D, Bhalla S, Zimmerman B, Sigel K, Gabrilove J. Protective role of BTK inhibitors in patients with chronic lymphocytic leukemia and COVID-19. Br J Haematol. 2020.

8. Baumann T, Delgado J, Montserrat E. CLL and COVID-19 at the hospital clinic of Barcelona: an interim report. Leukemia. 2020.

9. Treon SP, Castillo J, Skarbnik AP, Soumerai JD, Ghobrial IM, Guerrera ML, et al. The BTK-inhibitor ibrutinib may protect against pulmonary injury in COVID-19 infected patients. Blood. 2020;135:1912-15.

10. de Weerdt I, Hofland T, de Boer R, Dobber JA, Dubois J, van Nieuwenhuize D, et al. Distinct immune composition in lymph node and peripheral blood of CLL patients is reshaped during venetoclax treatment. Blood Adv. 2019;3:2642-52.

11. Robert Koch-Institut. COVID-19-Dashboard 2020. https:// experience.arcgis.com/experience/478220a4c454480e823b17327 b2bf1d4. Accessed 2 June 2020.

12. Verity R, Okell LC, Dorigatti I, Winskill P, Whittaker C, Imai N, et al. Estimates of the severity of coronavirus disease 2019: a model-based analysis. Lancet Infect Dis. 2019;20:669-77.

13. Riches JC, Davies JK, McClanahan F, Fatah R, Iqbal S, Agrawal $\mathrm{S}$, et al. $\mathrm{T}$ cells from CLL patients exhibit features of T-cell exhaustion but retain capacity for cytokine production. Blood. 2013;121:1612-21.

14. Diao B, Wang C, Tan Y, Chen X, Liu Y, Ning L, et al. Reduction and functional exhaustion of $\mathrm{T}$ cells in patients with coronavirus disease 2019 (COVID-19). Front Immunol. 2020;11:827.

15. Guan W-J, Liang W-H, Zhao Y, Liang H-R, Chen Z-S, Li Y-M, et al. Comorbidity and its impact on 1590 patients with COVID-19 in China: a nationwide analysis. Eur Respir J. 2020;55:2000547. 